\title{
Framing Outcomes and Programming Assessment for Digital Scholarship Services: A Logic Model Approach
}

\section{Meris Mandernach Longmeier and Sarah Anne Murphy}

\begin{abstract}
Assessing digital scholarship services offered either through academic libraries or elsewhere on campuses is important for both program development and service refinement. Digital scholarship support is influenced by fluid campus priorities and limited resources, including staffing, service models, infrastructure, and partnership opportunities available at a university. Digital scholarship support is built upon deep, ongoing relationships, and there is an intrinsic need to balance these time-intensive collaborations with scalable service offerings. Therefore, typical library assessment methods do not adequately capture the sustained engagement and impacts to research support and collaboration that come from digital scholarship services. This article discusses the creation of a logic model as one approach to frame assessment of digital scholarship services in the university environment.
\end{abstract}

\section{Introduction}

Centers for digital scholarship in higher education take many different forms. Some focus on advanced visualization support, others act as research and development branches of their parent organization, while still others offer services focused on digital humanities. A 2014 EDUCAUSE report differentiated digital scholarship centers from traditional research institutes due to their philosophy as service organizations. Staffed by experts with specialized skills supporting work with digital outputs, "digital scholarship centers focus on relationships, extending the ways in which librarians and academic computing professionals relate to and work with faculty (and often students) and their scholarly practices." ${ }^{1}$ In this way, the expertise available at the center allows researchers to deepen their knowledge, refine their own work, and collaborate with others on interdisciplinary topics. With those outputs in mind, it is unsurprising that digital scholarship centers reside on campus in libraries or in IT organizations, since both provide broad interdisciplinary support and their services are available to all campus researchers, faculty, staff, and students. Libraries and librarians, in particular, have emerged as experts, collaborators, and connectors to services and resources across the university. As Clay observes, while "libraries become more engaged with the process and application of research and seek to become embed-

Meris Mandernach Longmeier is Associate Professor and Head of Research Services at The Ohio State University Libraries, email: longmeier.10@osu.edu; Sarah Anne Murphy is Professor and Data Literacy E Visualization Librarian at The Ohio State University Libraries, email murphy.465@osu.edu. @ 2021 Meris Mandernach Longmeier and Sarah Anne Murphy, Attribution-NonCommercial (https://creativecommons.org/licenses/by-nc/4.0/) CC BY-NC. 
ded into research workflows [their] focus has shifted from the consumption to the creation of scholarship (134)." 2

While services offered through these digital scholarship centers vary, little has been found in the literature about assessment methods of the centers and the impact they have on campuses. In times where financial pressures on campus are growing and a stronger need to show return on investment prevails, digital scholarship centers need to develop metrics that communicate the value and impact that these services have on research support and how collaborations forged in these spaces enrich research outputs for the institution. Additionally, typical library assessment metrics do not adequately capture the sustained engagement and impacts that follow from digital scholarship consultation and collaboration efforts. By creating logic models, focused on long-term goals, services, and spaces where digital scholarship support is offered, digital scholarship centers can evolve based on defined metrics and assessment data, both qualitative and quantitative. This article covers the development of a logic model as an assessment framework for digital scholarship support. It reviews the literature of both digital scholarship center assessment and logic model development, provides the context of the services available at The Ohio State University Libraries (University Libraries), discusses the development process of the logic model, and highlights both successes and challenges of implementing the logic model to plan for digital scholarship services.

\section{Literature Review}

Several universities describe the creation and evolution of services supporting digital scholarship. With names such as Scholars' Commons, Research Commons, Research Hub, Scholar's $\mathrm{Lab}$, among others, some mirror the ethos present in the commons movement of the 1990s, when libraries intentionally paired expertise and technology-enhanced spaces to address emerging user needs. Others emerged due to a need for digital humanities support, which required multiple and varied technologies that were unfamiliar to researchers. Ultimately, the digital scholarship center functions as a space, either physical or virtual, that provides connections to services and resources that support research. In several instances, these centers reside in libraries or in partnership with libraries due to the fact that library services naturally align to discipline-neutral approaches, and library spaces are already established as incubators for scholarship. ${ }^{4}$

Each digital scholarship center has a different flavor of research support, just as every campus has different areas of specialties. The ideal suite of services available through a digital scholarship center matches that individual campus's research needs or emerging areas of interest. The names of many digital scholarship centers reflect the services they provide, which can include any of the following: data analysis and management, data visualization, digital humanities, research metrics, or spatial analysis. At Georgia State University, for example, the focus is on large data visualization capabilities through the Collaborative University Research and Visualization Environment, otherwise known as CURVE. ${ }^{5}$ Other names, such as the University of Virginia's Scholar's Lab, are less descript. This program grew out of a need for deep digital humanities support and has evolved into a service based on community building and building a shared culture for experimentation and innovation in research. ${ }^{6}$ Some centers, such as the University of Illinois at Urbana-Champaign's Scholarly Commons, provide a broad suite of services, including scholarly communication, data analysis, digitization services, user experience technology, and innovative teaching and learning resources. ${ }^{7}$ Others, like North Carolina State University's Hunt Library, offer expansive visualization resources and expertise in 3D printing and maker mentalities. ${ }^{8}$ 
Digital scholarship centers frequently must forge relationships with other campus units to provide expertise or technology support for researchers. While the missions and services of these units are ultimately aligned to provide exemplary research support, measures of success may differ among various units across campus. Without defined metrics and shared assessment goals for all key stakeholders of a digital scholarship center, campuses run the risk of reporting data that are easy to track, rather than those that capture the transformative nature of the work, where ideas are shared, collaborations are forged, and assumptions are challenged.

Few centers assess services holistically, focusing instead on individual research support areas, such as data management ${ }^{9}$ or digital humanities services. ${ }^{10}$ Early reporting of digital scholarship centers focuses around advocating for resources, developing spaces, and forming partnerships. ${ }^{11}$ The ARL SPEC Kit 350 on Supporting Digital Scholarship details assessment methods employed in libraries deploying digital scholarship support. ${ }^{12}$ Current metrics primarily report counts of projects supported, track consultations with faculty, students, and research support staff, and record the numbers of workshops and other educational endeavors. These counts, ARL reported, have supported internal improvement of services, advocacy for additional staff, or reconfiguring spaces. In the 2019 Report of a Learning Spaces Collaboratory (LSC) and the Coalition for Networked Information (CNI) Roundtable on Libraries as Spaces for 21st Century Learners \& Learning, Joan Lippincott stressed the importance of assessing library spaces and encouraged a needs assessment around a specific project to establish goals. The report highlights the importance of creating measurement strategies as part of space planning to examine trends around space development and use (Goldenberg-Hart, 2019). ${ }^{13}$ Assessment of space and service use need not stop once planning is completed. Typical traditional library assessment metrics do not adequately capture the sustained engagement and impacts that follow from digital scholarship consultation and collaboration efforts; therefore, a new approach must be employed to assess the refinement of services offered.

\section{Why a Digital Scholarship Center Needs a Logic Model}

Logic models offer a "visual approach to the implicit maps we all carry in our minds about how the world does or should work."14 In the evaluation community, this implicit understanding is referred to as program theory, or how stakeholders perceive a program might work. ${ }^{15}$ Logic models offer the staff of a digital scholarship center the ability to link the program's resource investments and planned activities with the program's intended outcomes, by visually displaying the theory driving the program. The model accomplishes this by depicting the complex relationships among various program components that, when integrated, will lead to impactful change. Logic models offer a framework to systematically assess or evaluate a program's effectiveness, outlining the fundamental assumptions either guiding a program or on which a program rests. They are useful tools for designing, planning, and communicating the results of a program, as well as determining program feasibility, assessability, and applicability or generalizability of the program to other settings and populations. ${ }^{16}$

References to using logic models for the development and evaluation of programs are sparse in the library literature. Hamasu and Kelly speculate that this may reflect that "librarians are unwilling to go through the arduous process of examining their programs, articulating their goals and desired outcomes, establishing measures of success, and documenting their work." ${ }^{17}$ The National Network of Libraries of Medicine Midcontinental Region reported 
using logic models to plan and evaluate programs for purposes of communicating their annual achievements to their funding agency, the National Library of Medicine. ${ }^{18}$ Stoddart and Weinraub Lajoie discussed the logic model as a tool to identify assessment opportunities and facilitate communication regarding how their information technology department supports a library strategic plan in relation to student success and faculty productivity. ${ }^{19}$ Cooper used a logic model as a tool to structure a comparison of the roles of an informationist in contrast to a general medical librarian." ${ }^{20}$ Measures That Matter, an initiative of the Chief Officers of State Library Agencies focused on evaluating the collection of public library data, is supported by a logic model (found here: https://measuresthatmatter.net/measures-that-matter-logic-model/) that outlines the project's activities, engagement strategies, and intended outcomes. ${ }^{21}$ Two American Library Association (ALA) Emerging Leaders teams working with the Association for Library Service to Children in 2014 and 2015 promoted logic models to support the evaluation of youth services, noting the tool not only helps to plan programs, but engages stakeholders in program development. ${ }^{22}$

Good logic models are created when stakeholders come together to articulate the intended impact of a program, based on their understanding of a community's needs, and the stakeholders' underlying assumptions about what drives these needs. By writing the logic model in concert with one another, stakeholders develop a shared understanding of the underlying theory of the program. The exercise also forces the stakeholders to describe their programmatic strategy using specific language and terms that facilitate evaluation of the program. ${ }^{23}$ When writing logic models, the term stakeholder should be defined broadly. Anyone "with an interest in or people likely to benefit from the program" should be included or involved in the model's development. ${ }^{24}$

Logic modelling is a messy, iterative process. Programs are inherently complex, and stakeholders often struggle to achieve consistent consensus when determining the interventions required to impact the community they have targeted. Engaging stakeholders in the modeling process recognizes that "multiple realities or views of program performance" exist. This complicates stakeholders' ability to reach a mutual understanding of what constitutes program success. To develop "a shared vision of how the program is supposed to work... persistent discovery and negotiation between and among stakeholders" is required..$^{25}$ The process of crafting a logic model creates a shared understanding of how the program should work, as well as "expectations for resources, customers reached and results." 26 A completed logic model also serves as a communication tool, helping organizations to sell needed programs to funding agencies or to share the "applicability and generalizability of programs to other settings and populations." 27 Thus, logic models are not only useful for conceiving new programs, but also serve to improve existing programs, operationalize programs, and disseminate program results.

\section{Creating a Logic Model and Data-Gathering Plan for the Research Commons}

University Libraries' Research Commons model of services revolves around four pillars: teaching, consultations, referrals, and showcasing research. These pillars support areas of need identified within the research lifecycle from planning research, to conducting research, to effectively publishing research, to highlighting the impact of the scholarship (see figure 1). Programming predated the research commons space itself and began in 2014 with workshops and consultations. The research commons, a 10,000 square foot space opened in January 2016, 
provides spaces designed with maximum flexibility, namely movable furniture and walls, to meet current and future planned service needs.

Current research commons services concentrate on the digital humanities, data services, data visualization, geospatial analysis, and examining research impact. Services, programs, and space offerings are primarily designed to support the research endeavors of Ohio State faculty and graduate students. The research commons provides a venue for this demographic to highlight their research products and to improve their abilities to measure their research analytics and manage their online identities. The venue itself supports collaboration. Research groups meet regularly in the space to use its interactive visualization capabilities. Workshop offerings include instruction on a wide variety of digital scholarship methods with an emphasis on open source tools, including text analysis, data visualization basics, introduction to geospatial analysis, basics of human subject research, and managing a digital scholarship project. In some areas (such as GIS), workshops are developed and delivered in collaboration with university partners to increase the number and types of offerings and enhance the capacities of both units.

The staff in the research commons (11 FTE, plus student workers) includes the head of

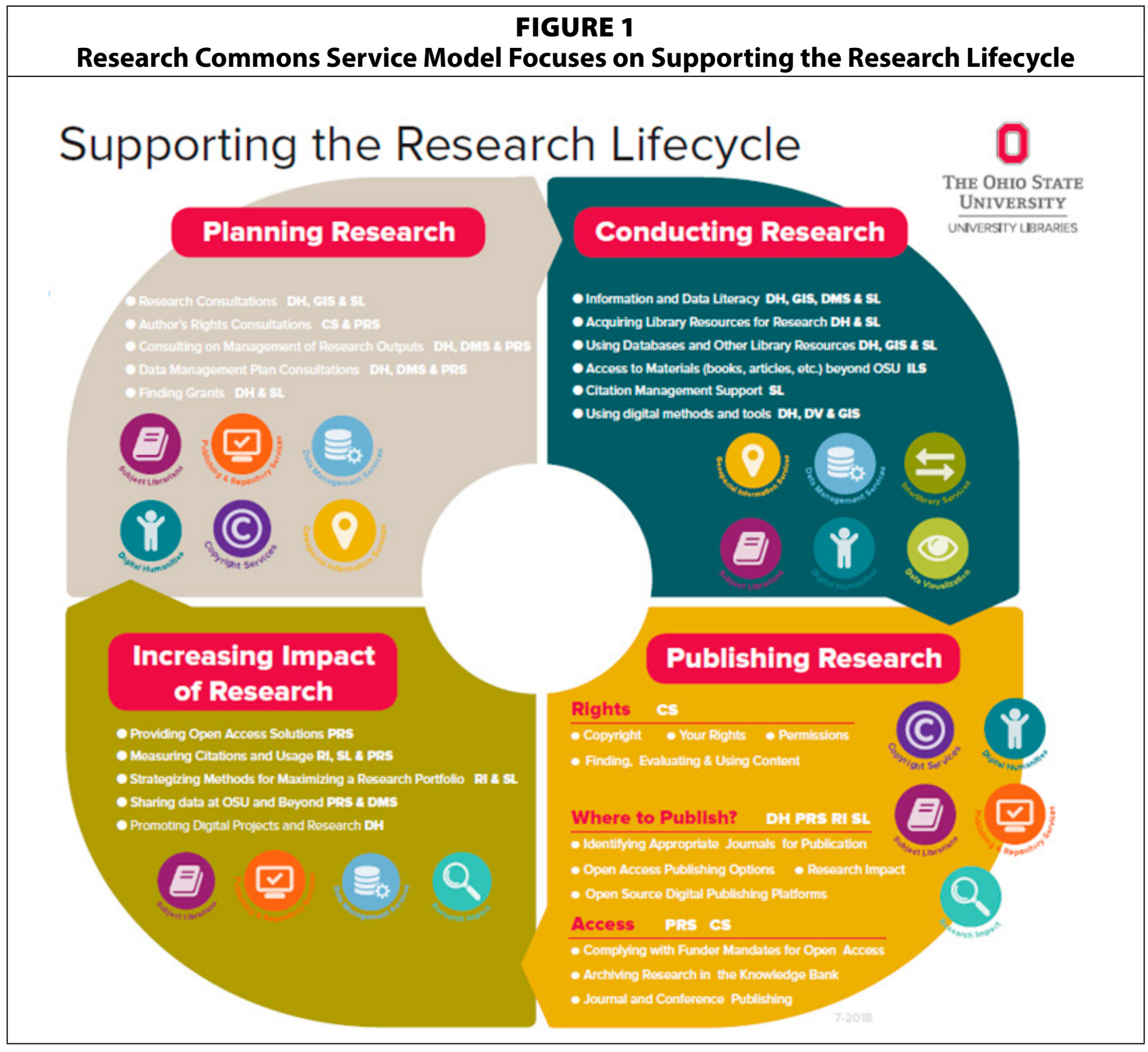


research services, a program manager, a public services coordinator, an IT specialist, a data literacy and visualization librarian, a data visualization specialist, a research impact librarian, a digital humanities librarian, a geospatial services librarian, a research data librarian, and a data services specialist. Organizationally within the libraries, this unit reports to the Associate Dean of Research and Education (see figure 2). The program manager oversees the day-to-day operations; the public services coordinator manages the concierge desk, oversees student workers, and triages requests; the five librarians provide instruction, consultations, and referrals within their assigned areas of functional expertise; and the head of research services provides strategic direction for the services and advocates for additional staffing.

The team partners with other Ohio State research services units, such as Discovery Themes,

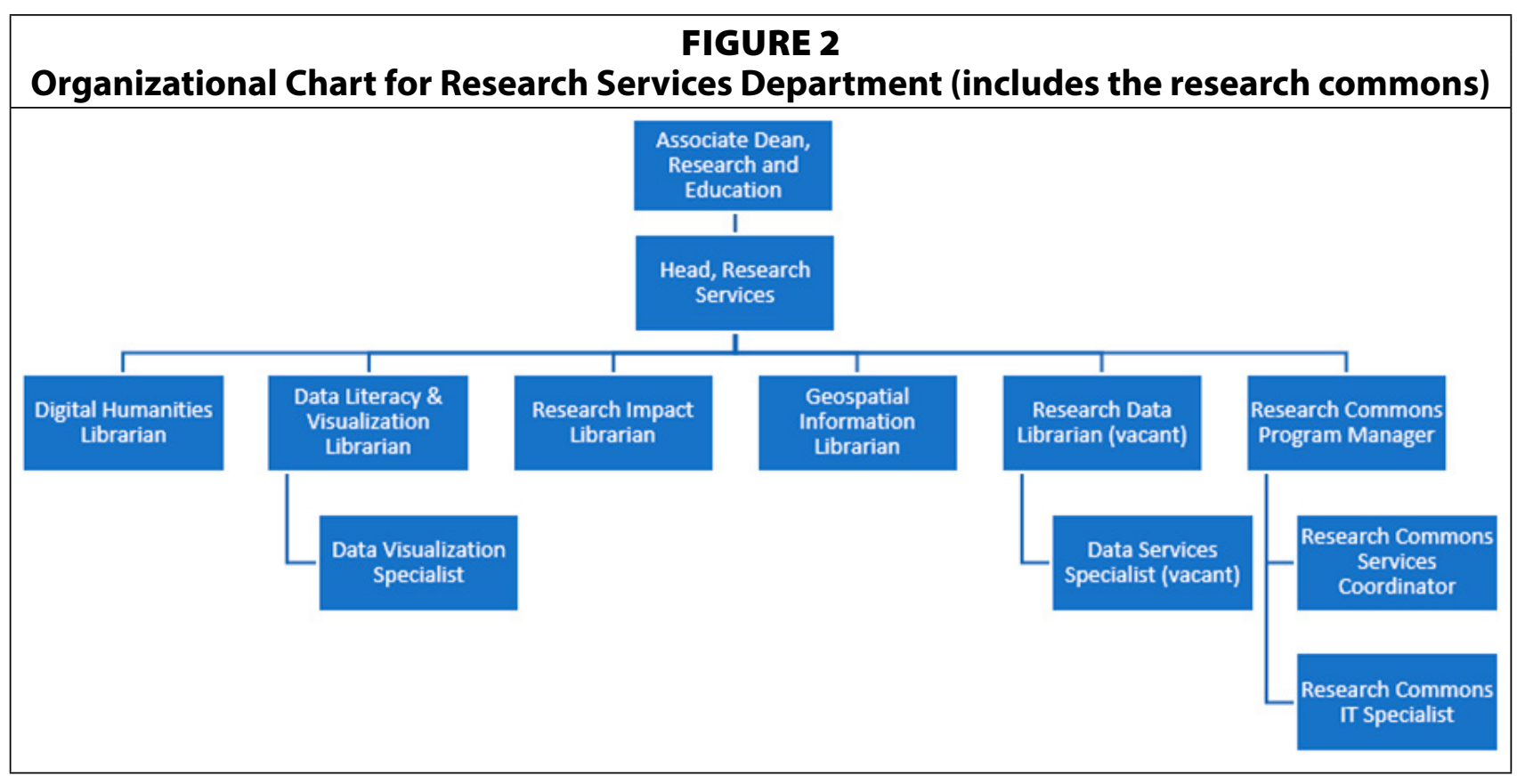

a university-wide, interdisciplinary research institute; the Research Development Office, which matches funding opportunities with specific research initiatives on campus; and the Industry Liaison Office, which connects corporations with university-based research personnel and activities. One of the greatest achievements of the research commons has been its extensive partnership network across campus and the extent to which it is well-known, promoted, and integrated into service offerings of these partner units and used well by them as a space for meetings, events, and presentations for the campus community.

Initial success measures were established during the design phase of the research commons space as the architects desired articulated success measures and outcomes to guide the development of the space (see appendix). These measures and outcomes were grouped together into seven categories: measuring traffic in physical and virtual spaces; creating a user community or group of repeat users; partnership and collaboration breaking the silos and facilitating cross-departmental research; breaking the mold and attracting our target audience; being seen as a valued resource; and long-term impact on research at The Ohio State University. Though developed in consultation with the staff in the research commons, no formal implementation plan was established to track these metrics as the space and services 
were still under development. However, these initial success measures informed several areas in the creation of the logic model and data-gathering plan.

Since opening the physical space in 2016, a substantial volume of data on the use of the services and the space has been collected. Staff in the research commons use SUMA ${ }^{28}$ to collect hourly data detailing how space is used. Software integrated with the research commons scheduling system tracks the number of consultations made via the online request form. An online registration/check-in system is used for all workshops and events to monitor attendance. Reservations for project rooms and larger meeting room schedules are captured as well. Many users provide informal feedback indicating their appreciation for the space, individual services, and opportunities to find research partners. Individual surveys are distributed at all workshops and trainings to measure immediate educational outcomes. These surveys also act as a means of gathering suggestions for additional programming ideas. The data collected are plentiful; however, this data does not always align with or help to answer whether key success measures are being met. For instance, while individuals were providing favorable feedback, it was harder to assess why researchers regularly using the space were often unaware of services, or why some researchers opted not to use the space at all.

After a year and a half, when the staff attempted to use the architect's success measures, several serious limitations were observed with the research commons' original assessment model. Little was known about several aspects of research the service supported, such as breaking disciplinary boundaries, enabling grant submissions, or working on longer-term projects. No information examining the balance between direct researcher use of the space versus researcher support units using the space was available. The output measures, while useful, failed to capture the full impact of the service.

The research commons' initial success measures mainly identified outputs rather than outcomes. This limited the library's ability to craft effective, impactful narratives around successes. After consulting with University Libraries' assessment coordinator, the research commons decided a logic model with a corresponding data collection plan was needed. The assessment librarian led the research commons leadership and operational staff, henceforth known as "the team," through several worksheets found in the W.K. Kellogg Foundation Logic Model Development guide to draft an effective logic model and data-gathering plan. The team first identified the various communities and stakeholders served by programs of the research commons, including users, partners, library staff, and library administration. They then reviewed and assessed the various stakeholders' needs and articulated the underlying assumptions regarding these communities' needs for impactful change. Articulating the outcomes or changes stakeholders wanted to see as a result of the activities and services provided through the research commons program with a linked series of short-term, medium-term, and long-term outcome statements was one of the most challenging parts of the process. These outcomes may be realized either within an academic community or among program participants. The team worked to identify what behavioral change would be present to define success of the program.

Outcomes are commonly expressed as changes observed in participants' knowledge, affect, skills, and abilities. A common short-term outcome for a library instruction program, for example, may be individuals who attend $x$ class will learn to use a specific research tool efficiently and effectively. The ultimate goal for an academic library and the greater university, however, is an information-literate student who, following graduation, becomes an engaged 


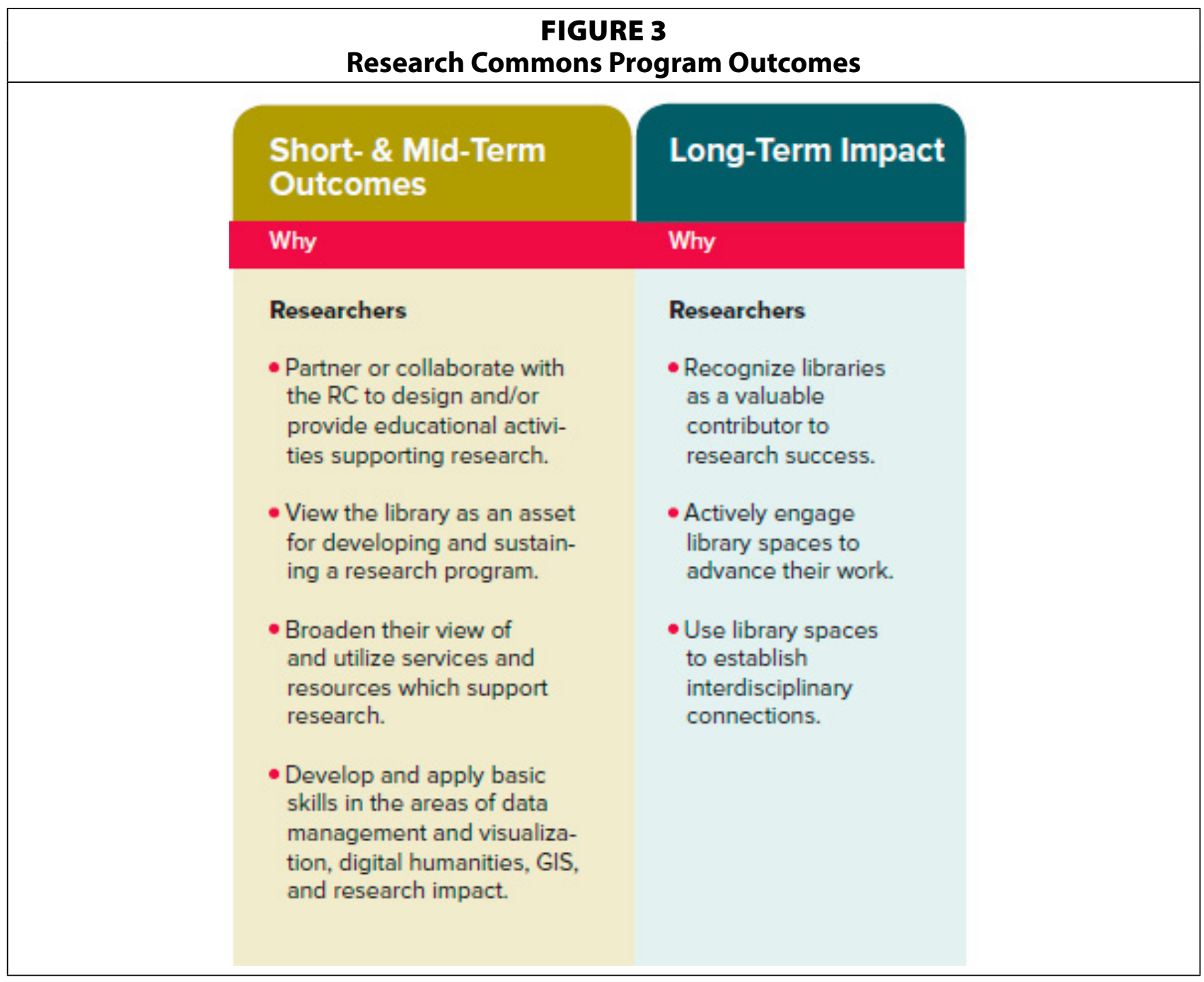

citizen within his or her community. In a digital scholarship center, outcomes are not always focused on students. Outcomes may instead capture the partner relationships needed to influence researchers' long-term behavior or may focus on increasing interdisciplinary research among faculty and graduate students. The team found outcome creation similar to the backwards design approach to course development. Focusing on the why of the program, the needs assessment, and the underlying assumptions for the research commons program, the team scheduled a series of three conversations using the W.K. Kellogg Foundation materials. The team detailed both the short- and mid-term outcomes (3-5 years) and long-term impact (10 years) for the research commons through this process (see figure 3 ). These outcomes reflected the library's desire to develop researchers to view the library as an integral asset of their research workflow.

The team then identified the activities, actions, or interventions they anticipated would induce the change. For digital scholarship centers, activities may include anything from training sessions, to individual consultations, to large events that showcase research outputs, or simply providing collaborative workspaces. Activities represent the intentional interventions that, when implemented, will realize impactful change. Ideally, program activities are evidence-based and grounded in the stakeholder's understanding of the community they serve. Last, the team identified the resources needed to execute the interventional activities, 
including human, financial, and capital investments, and linked these resources to the activities and intended outcomes.

There is no right or wrong way to write a logic model. Linkages among program investments, activities, and outcomes are not necessarily linear. Some program activities might address two to three outcomes, while others will only address one. Multiple examples of nonlinear logic models exist in the evaluation literature. ${ }^{29}$ Regardless of how the logic model is represented, readers must be able to discern the linkages among the programmatic investments, activities, and intended impact or outcomes. Stakeholders must step back and evaluate whether the model is complete. Does the model explicitly define the program theory by identifying the linkages among the programmatic investments, interventions, and intended impacts? Is it realistic? Is the program, as defined, measurable in terms of outputs and outcomes? When read from left to right, does the logic model outline a series of If ... then statements, such as if we invest the following resources, then we can provide the following activities or interventions? Then our community will realize the following outcomes that will then lead to lasting impact or change. A well-written, concise, high-quality logic model facilitates evaluation, by "point[ing] out the key features and show[ing] the relationships that need assessment." 30

The team revisited assumptions and checked its linkages among program investments, activities, and outcomes through two subsequent meetings spaced at one-month intervals. The spacing of these conversations allowed the team to step away, gather feedback from the rest of the research services department, and incorporate revisions into the next version of the research commons program implementation logic model shown (see figure 4). The time

\begin{tabular}{|c|c|c|c|c|}
\hline \multicolumn{5}{|c|}{$\begin{array}{l}\text { FIGURE } 4 \\
\text { Research Commons Program Logic Model }\end{array}$} \\
\hline \multirow[t]{2}{*}{ Resources } & Activities & Engagement Strategies & $\begin{array}{l}\text { Short- \& Mid-Term } \\
\text { Outcomes }\end{array}$ & Long-Term Impact \\
\hline & What, Dally Work & Actions & Why & Why \\
\hline $\begin{array}{l}\text { - Multiple flexible, } \\
\text { technology enriched, } \\
\text { collaborative spaces } \\
\text { - Knowledgeable } \\
\text { technical/ } \\
\text { professional staff } \\
\text { - Planning assistance } \\
\text { for educational and } \\
\text { research showcase } \\
\text { events } \\
\text { - One-stop shop for } \\
\text { broad, multifaceted } \\
\text { research support }\end{array}$ & $\begin{array}{l}\text { - Support facultyl } \\
\text { graduate students to } \\
\text { develop a sustained } \\
\text { research program } \\
\text { - Develop speclallzed } \\
\text { training resources } \\
\text { - Research advice/ } \\
\text { consultations } \\
\text { - Strategic partnerships } \\
\text { - Communication plan }\end{array}$ & $\begin{array}{l}\text { Promote best practices and } \\
\text { provide support for proactively } \\
\text { planning, executing, and managing } \\
\text { research. } \\
\text { Provide training, forums, and } \\
\text { events which: } \\
\text { - Support peer-to-peer learning } \\
\text { - Foster interdiscliplinary } \\
\text { connections } \\
\text { - Teach researchers to develop } \\
\text { and apply basic methodological } \\
\text { and technological skllls for data } \\
\text { visualization, digital humanitles, } \\
\text { and GIS } \\
\text { - Advance development of skills } \\
\text { required for a sustalned research } \\
\text { program, Including grant seeking. } \\
\text { data management, responsible } \\
\text { research practices, and scholarly } \\
\text { publication }\end{array}$ & $\begin{array}{l}\text { Researchers } \\
\text { - Partner or collaborate with } \\
\text { the RC to design and/or } \\
\text { provide educational activl- } \\
\text { tles supporting research. } \\
\text { - Vlew the Ilbrary as an asset } \\
\text { for developing and sustaln- } \\
\text { Ing a research program. } \\
\text { - Broaden their vlew of } \\
\text { and uttlize services and } \\
\text { resources which support } \\
\text { research. } \\
\text { - Develop and apply basic } \\
\text { skllls In the areas of data } \\
\text { management and visualliza- } \\
\text { tlon, digital humanitles, GIS, } \\
\text { and research Impact. }\end{array}$ & $\begin{array}{l}\text { Researchers } \\
\text { - Recognize Ilbrarles } \\
\text { as a valuable } \\
\text { contributor to } \\
\text { research success. } \\
\text { - Actively engage } \\
\text { llbrary spaces to } \\
\text { advance their work. } \\
\text { - Use library spaces } \\
\text { to establish } \\
\text { Interdisciplinary } \\
\text { connections. }\end{array}$ \\
\hline \multicolumn{5}{|c|}{ 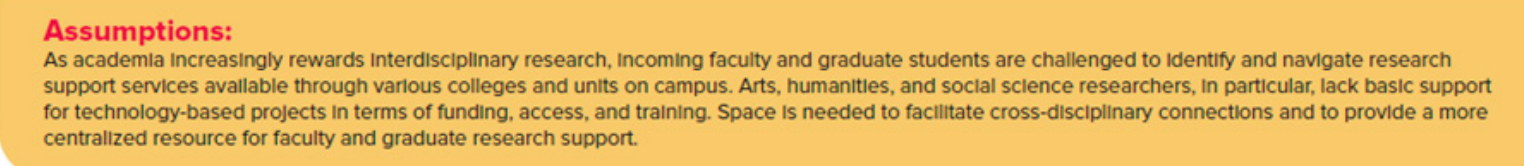 } \\
\hline
\end{tabular}




\begin{tabular}{|l|l|l|l|l|}
\hline \multicolumn{5}{|c|}{ Excerpt from the Data-gathering Plan That Details Data Involved in Assessing One } \\
Midterm Outcome and One Long-term Outcome
\end{tabular}

for reflection was a key to ensuring that language included in the logic model adequately captured the work of the program and allowed for revisions to happen throughout the creation process. The team then worked with University Libraries' graphic designer to create an impactful visualization of the model to share with the rest of University Libraries to communicate the purpose of the program and provide an example of a best-practice example for structuring program evaluation.

To complete the project, the team wrote a corresponding data-gathering plan (excerpt included as table 1) to link the outcome statements to specific assessment activities, including surveys, focus groups, and the more typical daily collection of service data. A living document, the data-gathering plan, focuses assessment activities and offers specific indicators of success. ${ }^{31}$ The practical data-gathering plan includes a timeline for assessment activities, to help guide and pace the research commons assessment work, as well as specific indicators of success, to allow librarians and staff to determine whether research commons activities and initiatives realized change. It also assigns specific assessment tasks to librarians and staff, to ensure the work is completed. A schedule for revisiting both the logic model and data-gathering plan was set for three-year and one-year evaluations, respectively.

\section{Discussion}

Overall, the creation of the logic model allowed the team to share the key engagement strategies and intended outcomes for the research commons program with internal and external stakeholders. The finished model could easily be incorporated into presentations, both within the university and externally at local and international conferences. One limitation of the 
polished, presentation-quality logic model, was a general feeling within the department, especially those not involved with the team's initial versions, that the work was complete and the model itself was established and could no longer be adjusted-even though, by nature, a logic model is a living document that can and should be continually reevaluated. Until the logic model was presented in tandem with the data-gathering plan, colleagues were not able to see their role in the assessment process, at which point they thought all of the details were finalized and were concerned that their areas were not adequately represented. Therefore, other libraries and institutions interested in adopting a logic model approach to assessment work must consciously develop several, varied mechanisms to engage individuals vested in the outcome of the process and continually solicit their feedback throughout the model's creation.

The creation of the logic model propelled a greater understanding of what the program is trying to address and helped the research commons to define its space as a standalone service itself. The logic model provided a frame for ongoing discussions within the department centered on its goals and aspirations. It also aided managerial discussions, showcasing a process for discerning and communicating programmatic intention and assessment. The authors presented the model to the University Libraries' management committee and other research commons campus partners to highlight the services offered by the research commons to other units for proactively planning, executing, and managing research.

Developing the logic model allowed the Libraries to critically examine how it defines research services in terms of training, consultations, forums, events, and providing a space for research itself. The process revealed a gap in communicating and documenting long-term successes as evidenced by the development of sustained, long-term relationships and the difficulty of gathering evidence of impact, such as research commons staff and faculty being written into grants, partnering on the creation of scholarly outputs, and the value of being a connector to enable research on campus. Current assessment activities focus on gathering impact stories and reviewing post-program survey data. Librarians and staff are refining the data-gathering plan and developing focus groups and user surveys aligned with the articulated indicators of success. As the program matures, both the logic model and the data-gathering plan will be examined and updated to reflect the evolving theory of change driving the research commons program as it works to support the developing needs of the Ohio State research community.

\section{Conclusion}

Logic models are a powerful tool for articulating both long-term and short-term outcomes and allow creators to define the resources and engagement strategies required to achieve sustained change. They are one of many tools available that facilitate digital scholarship service program assessment. As digital scholarship services are increasingly offered on campuses, libraries or other campus units offering these services should build assessment methods into their ongoing program evaluation process to reevaluate services and respond to emerging areas of user needs. Logic models are an ideal tool for emerging areas of library research support as they allow the more relationship-based support of digital scholarship services impact to be captured.

The overarching recommendation for any digital scholarship center examining logic models as a potential assessment tool would be to ensure that the measures of success are detailed early in the process and data-gathering plans have both qualitative and quantitative measures to capture the innately relational work done in the areas of digital scholarship 
support. Additionally, the logic model is a living document that can and should be revised to consider the rapidly evolving set of services needed to support emerging areas of interdisciplinary scholarship.

\section{Acknowledgments}

The authors would like to thank Joshua Sadvari and Nicole Hernandez for their assistance in developing the logic model and data-gathering plan and the research services faculty and staff for responding to the initial model and data-gathering plan and offering suggestions for improvement. 


\section{APPENDIX. The Research Commons: Relating Success Measures and Assessment Techniques}

Developed by Joshua Sadvari and Meris Mandernach 2015

\section{1) Concept: "Traffic in Physical and Virtual Spaces"}

How Do We Know?

- Increased campus awareness overall (comparison to baselines from student marketing project)

- Headcounts of open spaces

- Workshop attendance (comparison to baselines from prior to space opening)

- Consultation appointments

- Room reservations

- Walk-in sign-in at Concierge Desk

- Google Analytics on website

- Ask Us chat sessions

- LibAnswers FAQ views by users

- LibAnswers entries by staff

\section{2) Concept: "Creating a User Community" (or "Repeat Customers")} How Do We Know?

- Event registration, appointment scheduling, and room reservation systems will allow for cross-referencing based on OSU username

- Server usage-storing project components on server implies return to continue project

- Mailing list subscribers

- Blog subscribers

- Followers/participants on social media platforms

\section{3) Concept: "Partnership (RC/experts) and Collaboration (RC/users and users/ users)"}

How Do We Know?

- Consistent presence of partners in space through room reservations (such as Writing Center facilitating research writing groups) and consultations (for example: copyright, funding, IRB, and the like)

- Ideas for and development of new programs in collaboration with partners

- Campuswide interest among research centers in working with RC to facilitate programming, especially research showcases (and in some cases, establishing ongoing partnerships)

- Interest among campus experts (not necessarily partners) in facilitating interdisciplinary working groups around use of technology and software available in the RC

- Interest across campus in becoming a member of an RC interdisciplinary working group (in the same sense as the Writing Center's interdisciplinary writing groups)

- High attendance at social networking and showcasing events hosted in the RC, which would be the programs most geared toward fostering interdisciplinary connection and collaboration 


\section{4) Concept: "Breaking the Silos"}

How Do We Know?

- Event registration, appointment scheduling, and room reservation systems will allow for gauging the disciplinary range of users based on OSU username

- Room reservation system could ask person making the reservation to list all expected attendees based on OSU username (this would allow us to see if the collaboration spaces are being used by researchers in the same discipline or by groups of researchers from different disciplines)

\section{5) Concept: "Breaking the Mold"} How Do We Know?

- Changes to perceptions of 18th Avenue Library as a loud and crowded space used primarily by undergraduates (comparison to baselines from listening sessions and other surveys)

- Changes to perceptions of "Library as Place" among graduate students and faculty reflected in general responses and specific references to Research Commons in LibQual comments (comparison to baselines from previous LibQual surveys)

- Event registration, appointment scheduling, and room reservation systems will allow for gauging affiliation of users based on OSU username (this would allow us to assess whether use of the space differs from elsewhere in the Libraries; that is to say, corresponding to heavy use by faculty, graduates, postdocs, and research staff)

\section{6) Concept: "A Valued Resource" (or "Recruiting")}

\section{How Do We Know?}

- Periodic surveys of new users/registrants to gauge how they became aware of the space and decided to work there (was it recommended by a colleague?)

- Becomes a point of interest on department tours for incoming graduate cohorts and/or new faculty (number of requests for personal department tours and number of tours seen to be happening in the space)

\section{7) Concept: "Return on Investment"}

\section{How Do We Know?}

- Success rates of specific services facilitated within the space, such as:

- Getting limited submission or external grants (faculty) following red team review

- Getting internal grants (or external graduate grants) after consultation

- Getting a peer-reviewed publication after consultation or writing group participation

- "Researcher Portfolios" via the website (could be provided to heavy users of RC services and collaborators on specific projects)

- Provides individual researchers (or teams) with a venue for showcasing their work

- Provides OSU research community with a place to see what research is happening across the university (and potentially find collaborators through our virtual space)

- Provides us with an opportunity for peer-to-peer testimonials ("this is how the Research Commons helped me...")

- Provides us with an opportunity for longer-term tracking as researchers update information about ongoing projects, presentations and publications, grants, and so on ("this is what RC collaborators are accomplishing...") 
*These success measures and associated assessment techniques are based on our vision of the Research Commons at Ohio State. Further information can be gathered from our partners at OSU as well as comparable spaces at other universities to revise or add assessment techniques and gauge whether other measures of success should apply to us.

\section{Notes}

1. Joan Lippincott, Harriette Hemmasi, and Vivian Lewis, “Trends in Digital Scholarship Centers," Educause Review (May/June 2014).

2. David Clay, "Building Scalable and Sustainable Services for Researchers," in Developing Digital Scholarship: Emerging Practices in Academic Libraries, eds. Alison Mackenzie and Lindsey Martin (Chicago, IL: ALA Neal-Shuman, 2016), 121-38, https://doi.org/10.29085/9781783301799.008.

3. Lippincott, Hemmasi, and Lewis, "Trends in Digital Scholarship Centers"; Merinda Hensley and Steven J. Bell, "Digital Scholarship as a Learning Center in the Library: Building Relationships and Educational Initiatives," College \& Research Libraries News 78, no. 3 (2017): 155-58, https://doi.org/10.5860/crln.78.3.9638; Bryan Sinclair, "Commons 2.0: Library Spaces Designed for Collaborative Learning," Educause Review, no. 4 (2007).

4. Bryan Sinclair, "The University Library as Incubator for Digital Scholarship," Educause Review (June 30, 2016).

5. https://library.gsu.edu/services-and-spaces/spaces-and-technology/curve/ [accessed 13 December 2019].

6. https://scholarslab.lib.virginia.edu/ [accessed 13 December 2019].

7. https://www.library.illinois.edu/sc/about_us/ [accessed 13 December 2019].

8. https://www.lib.ncsu.edu/huntlibrary [accessed 13 December 2019].

9. Jeffrey C. Oliver et al., "Data Science Support at the Academic Library," Journal of Library Administration 59, no. 3 (2019): 241-57, https://doi.org/10.1080/01930826.2019.1583015.

10. E. Leigh Bonds, "First Things First: Conducting an Environmental Scan," dh+lib (January 31, 2018), https:// acrl.ala.org/dh/2018/01/31/first-things-first-conducting-an-environmental-scan/ [accessed 24 October 2019]; Thea Lindquist, Holley Long, and Alexander Watkins, “Designing a Digital Humanities Strategy Using Data-Driven Assessment Methods," dh+lib (January 30, 2015).

11. Joan K. Lippincott and Diane Goldenberg-Hart, “Digital Scholarship Centers: Trends \& Good Practice," Coalition for Networked Information (December 2014).

12. R. Mulligan, Supporting Digital Scholarship, SPEC Kit 350 (2016), https://publications.arl.org/SupportingDigital-Scholarship-SPEC-Kit-350/1.

13. Diane Goldenberg-Hart, "Libraries as Spaces for 21st Century Learners and Learning: Report of an LSC/ CNI Roundtable," CNI Fall 2018 Membership Meeting (2019), https://www.pkallsc.org/wp-content/uploads/2019/01/ Report-of-an-LSC-CNI-Roundtable.pdf [accessed 24 October 2019].

14. Lisa Wyatt Knowlton and Cynthia C. Phillips, The Logic Model Guidebook: Better Strategies for Great Results (Los Angeles, CA: SAGE, 2009), 4.

15. John A. McLaughlin and Gretchen B. Jordan, “Logic Models: A Tool for Telling Your Program's Performance Story," Evaluation and Program Planning 22 (1999): 66.

16. Riki Savaya and Mark Waysman, "The Logic Model: A Tool for Incorporating Theory in Development and Evaluation of Programs," Administration in Social Work 29, no. 2 (2005): 85-103, https://doi.org/10.1300/ J147v29n02_06.

17. Claire Hamasu and Elizabeth Kelly, "The Logic Model: More Than a Planning Tool," Performance Measurement and Metrics 18, no. 2 (2017): 159, https://doi.org/10.1108/PMM-08-2017-0032.

18. Hamasu and Kelly, "The Logic Model," 159.

19. Rick Stoddart and Evviva Weinraub Lajoie, "The Possibilities Are Assessable: Using an Evidence Based Framework to Identify Assessment Opportunities in Library Technology Departments," Evidence Based Library and Information Practice 9, no. 4 (2014): 29-43.

20. I. Diane Cooper, "Is the Information a New Role? A Logic Model Analysis," Journal of the Medical Library Association 99, no. 3 (2011): 191, https://dx.doi.org/10.3163\%2F1536-5050.99.3.004.

21. Chief Officers of State Library Agencies, "Measures That Matter," https://measuresthatmatter.net/measuresthat-matter-logic-model/ [accessed 24 April 2020].

22. Tom Bober et al., "Connecting Resources, Goals, Statistics, and Stories: Exploring Logic Models as a Means of Valuation in Youth Library Services," Association for Library Service to Children Board AC (2015), Doc 10a, www.ala.org/educationcareers/sites/ala.org.educationcareers/files/content/EL2015_Team\%20D_ALSC\%20 Report.pdf [accessed 14 February 2018]. 
23. Sarah Anne Murphy and Craig Gibson, "Programmatic Assessment of Research Services: Informing the Evolution of an Engaged Liaison Librarian Model," in Assessing Liaison Librarians: Documenting Impact for Positive Change, eds. Daniel C. Mack and Gary W. White (Chicago, IL: Association of College and Research Libraries, 2014).

24. Knowlton and Phillips, The Logic Model Guidebook, 45.

25. McLaughlin and Jordan, "Logic Models," 67.

26. McLaughlin and Jordan, "Logic Models," 66.

27. Savaya and Waysman, "The Logic Model," 98.

28. https://github.com/suma-project/Suma.

29. W.K. Kellogg Foundation, "Logic Model Development Guide," last modified 2004, https://www.wkkf. org/resource-directory/resources/2004/01/logic-model-development-guide.

30. Knowlton and Phillips, The Logic Model Guidebook, 10.

31. W.K. Kellogg Foundation, "Logic Model Development Guide," chapter 4, exercises 4-5, p43-48, templates $54-62$. 